\section{Nova et Vetera}

\section{EXETER'S MEDICAL HISTORY}

Exeter, with which Torquay is closely linked medically, has much that will interest members of the British Medical Association visiting Torquay for the Annual Meeting. Like other ancient cathedral cities it was in former days an important administrative metropolis. Its association with Drake and Raleigh will be well enough known, but as a medical centre it goes back at least to the twelfth century, when the first hospital was established for much the same reasons as those of St. Bartholomew's and St. Thomas's in London and that of the Holy Cross at Winchester-to care for pilgrims and lepers. This hospital of St. Mary Magdalene later became an almshouse.

Exeter had several other hospital foundations, some for the care of the aged, some for orphans. The latter became schools, one of which, the Blue Maidens Hospital (now developed into the modern Maynard Girls' School), has a special link with Torbay. On November 5, 1688, Prince William of Orange landed at Brixham with 15,000 troops of very assorted nationalities. His first major stopping-place en route for London, and the overthrow of James II, was at Exeter, which he entered on November 9. The weather was the worst that Devon can offer, and in wet seasons,

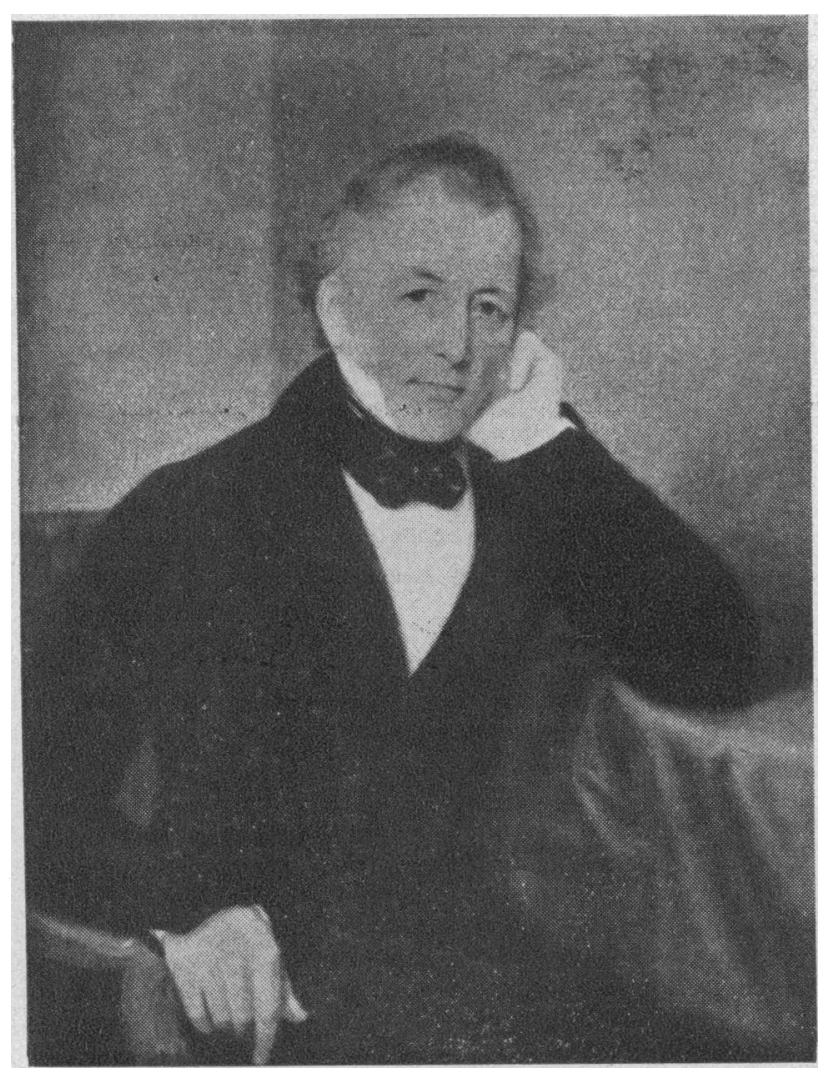

John Haddy James, 1788-1869.

such as the recent winter of $1959-60$, it can be really terrible. Prince William's troops suffered much from exposure. At his request the city fathers of Exeter established a temporary hospital at the Blue Maidens. Documents relating to this are still preserved, and in them are given details of the medical condition of soldiers, the drugs used, the provisions, and the names of the surgeons and of the women who looked after the men. William never paid his bill, and in 1706 the citizens appealed to Queen Anne for the sum involved, which amounted to $£ 3544 \mathrm{~s}$. $2 \frac{1}{2} \mathrm{~d}$. History does not relate whether it was ever paid.

The first hospital in the modern sense was completed in 1718: it is the present Exeter City Hospital, and it remained a municipal hospital until 1948, although its original buildings were destroyed by enemy action in 1942 . The first voluntary hospital, now known as the Royal Devon and Exeter Hospital, was founded in 1741, and was one of the first great provincial voluntary hospitals established in the eighteenth century. Its original buildings still remain and are in daily use. The board room is well worth a visit, a perfect example of the architecture of the time, with some magnificent portraits of its early worthies: three of them are by Thomas Hudson, the master of Joshua Reynolds, and two by John Opie (that of John Patch junior : surgeon is one of the greatest works of this master). Amongst these worthies are also portraits of Dean Alured Clarke, the founder, Thomas Glass, John Lee Dicker, John Patch senior (a portrait which much influenced Reynolds), and John Sheldon, F.R.S., an eccentric genius and one of the pupils of William Hunter, whom he followed as anatomist to the Royal Academy.

Thomas Glass, one of the founders and an early pioneer in vaccination, is also notable in having founded the Exeter Medical Library in 1787: this was greatly augmented by Bartholomew Parr, F.R.S., and by their followers to the present day. Dr. Glass had bequeathed his library to the Cathedral. In 1819 the medical leaders in the city persuaded the Dean and Chapter to allow this collection of books to form the basis of the bigger library established at the Royal Devon and Exeter Hospital, and there they remained until in 1947, the memory of the Dean and Chapter was refreshed by the approaching nationalization of the hospitals, and, although the library was independent of the Health Service, the Glass collection was reclaimed and is once more housed in the excellent Cathedral Library, which is administered by the University of Exeter but is kept at the Bishop's Palace. The Exeter Medical Library, now in two portions, contains most of the medical classics. It is an outstanding collection and should certainly be visited by those interested in medical history.

During the eighteenth century some sort of medical education was to be found at the Royal Devon and Exeter Hospital, and early in the nineteenth century, influenced by John Sheldon, impetus was given to the formation of a medical school, which continued until 1858 . Leaders in this were Samuel Barnes and John Haddy James. Barnes was a leading provincial oculist, and was one of the ancestors of the actress sisters Violet and Irene Vanbrugh. John Haddy James should particularly be remembered at this time, for he was one of those who assisted Charles Hastings in establishing the Provincial Medical and Surgical Association (which was to become the British Medical Association) in 1832. Ten years later he was president of a two-day meeting of the Association in Exeter. His efforts there met with the warm approval of Charles Hastings, as the following letter shows :

\section{Dear Mr. James,}

Worcester, August 13, 1842.

Ever since my return home $I$ have been in a contiriual whirl of business or I should have earlier written to congratulate you on the singularly successful meeting which we were so fortunate to have under your presidency. I can assure you with perfect truth, that on no occasion do I remember the presidential duties better performed, and every local arrangement was as satisfactory as possible - the Council are about to meet here this evening to make arrangements for the publication of the next Volume of Transactions and I think we shall agree to have a small volume printed as last year.

The question of Medical Reform seems to require no immediate attention but on this I shall probably find it necessary to correspond with you and if anything occurs to you pray write to me.

I am not aware of any subject connected with the association requiring immediate attention but $I$ shall expect to hear from you at any time that you may have suggestions to make to me.

I cannot write further for I am summoned away but you shall hear again.

Believe me yours truly,

Chas. Hastings.

P.S.-I have arranged for a full report of the meeting in the journal.

(The Journal had not yet received capital letter status.-N.C.)

(Continued at foot of next page) 


\section{To-day's Drugs}

With the help of expert contributors we publish below notes on a selection of drugs in current use.

\section{Phenazocine}

"Narphen" (Smith \& Nephew).

Chemistry.-Phenazocine is racemic 2'-hydroxy-5,9-dimethyl-2-phenethyl-6,7-benzomorphan, and has the following structural formula:

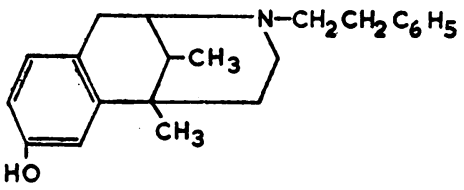

Pharmacology.-The analgesic potency of the laevo-isomer in mice was about 20 times higher than that of morphine. The dextro-isomer was approximately half as active as the laevo-rotatory form. Preliminary tests in monkeys indicated a low physical dependence on the drug. Similar results were obtained in man. Clinical trials suggest that $1.5 \mathrm{mg}$. given intramuscularly at four-hourly intervals controls postoperative pain adequately. Slightly higher doses were successfully used in patients with malignant disease. Phenazocine appears to be about three to five times more effective than morphine in producing analgesia in man.

Therapy.-The therapeutic indications are the same as for morphine. Phenazocine seems to be less liable than morphine to produce respiratory depression and vomiting, but more information on this and on its addictive properties is needed.

Side-effects.-Respiratory depression. Hypotension in 7 out of 160 patients. Constipation.

Contraindications.-The same as for morphine.

N.H.S. Busic Price.-10 1-ml. (2-mg.) ampoules, 18s. 9d.

(Continued from previous page)

This year, during the Annual Meeting of the B.M.A. in Torquay, there will be, for those interested, displays of books and documents at both the library at the Royal Devon and Exeter Hospital and at the Cathedral Library, Exeter, where can also be seen the famous Anglo-Saxon Book of Exeter.

Further information and references are given in my article "John Sheldon, F.R.S., and the Exeter Medical School" (Proceedings of the Royal Society of Medicine, 1959, 52, 231).

The portrait of John Haddy James is reproduced by kind permission of the Governors of the Royal Devon and Exeter Hospital.

Norman Capener.

\section{JENNER THE MAN}

There have been several lives of Jenner-from Dr. Baron's full and somewhat ponderous biography of 1827 to the excellent and authoritative work, $A$ Bio-bibliography of Edward Jenner, by W. R. LeFanu, published in 1951 .

Dorothy Fisk's biography presents Jenner from a different aspect.* She has assembled all the facts of Jenner's life with care and accuracy. She describes his upbringing, his coming to London as John Hunter's pupil, his return to Berkeley to practise, his study of the cuckoo, his introduction of vaccination, and his triumphs and disappointments resulting from this achievement. Her main purpose is to show us Jenner the man-the humane physician, the poet, the naturalist, the good husband and father, and the friend. The result is a delightful book which doctors will enjoy and can recommend to their patients and friends. One or two slips should be corrected in the next edition. On p. 109, for example, fleas are implicated as the vectors of Jenner's typhus instead of lice.

ARTHUR S. MACNALTY.

* Dr. Jenner of Berkeley. By Dorothy Fisk. (Pp. 288+vii ; illustrated. 25s.) London, Melbourne, Toronto: Heinemann. 1959.

\section{Correspondence}

Because of heavy pressure on our space, correspondents are asked to keep their letters short.

\section{Allergy to Tetanus Antitoxin}

SIR,-The article by Dr. I. B. Sneddon (May 14, p. 1468), describing a severe and prolonged allergic reaction after a test dose of $0.2 \mathrm{ml}$. of a 1 in 10 dilution of tetanus antitoxin, raises several points of interest. While an induced sensitization to an injection of tetanus antitoxin is not uncommon (horse-serum sensitivity is seen in the eczema, asthma, hay-fever group of patients), this seems to be the first recorded case of sensitivity developing to the very small amounts of tetanus antitoxin that normally would become airborne when giving an injection.

Sensitivity to streptomycin in nurses who give injections of streptomycin is a well-known hazard, and special recommendations have been promulgated to diminish such sensitization arising. Nurses who become very sensitive may reach the stage when merely going into a ward where streptomycin is given will start off irritation of the eyelids. The antigenic dose involved in these acutely sensitive personnel must be infinitesimal. If a test dose is given to such a patient, $1 \mu \mathrm{g}$. may be a gross overdose. In other words, a test dose on a nurse with suspected sensitivity must be at least 100,000 times less than the patient-dose. On the other hand, a patient receiving 1 gramme streptomycin daily who becomes sensitized to the drug can safely be test-dosed with a dilution of 1 in 10 .

It is very easy to be wise after the event, but Dr. Sneddon states "despite the absence of an allergic history." Surely the history clearly indicated that it was likely that his patient was allergic and allergic to a very high degree? A test dose of $0.2 \mathrm{ml}$. of a 1 in 10 dilution was likely from the patient's history to cause a severe reaction. Such a test dose in a known horse-sensitive patient has been known to cause death. I would therefore make the plea that the much simpler and safer procedure of using a prick test dose (this can also be called a skin test) of the undiluted antitoxin first be carried out if sensitivity is suspected. This introduces about five millionths of an $\mathrm{ml}$. which is one thousand times less than the dose used by Dr. Sneddon. Even this dose very occasionally will cause a mild general allergic reaction.

Dr. Sneddon states that tetanus toxoid does not contain anything likely to cause sensitization. I agree that tetanus toxoid is the least likely of all prophylactic injections to cause allergic trouble. However, it has caused death, and I believe that with the new synthetic casein medium that is used to grow the tetanus bacillus sensitization to this vaccine is on the increase, especially if looked for. It is as well to remember that any injection may contain known or unknown allergens. Moreover, any injection which gives rise to protective antibodies may also sensitize and give rise to allergic antibodies. - I am, etc.,

$$
\begin{aligned}
& \text { Allergy Department. A. W. FRANKLAND. } \\
& \text { Wright-Fleming Institute of Microbiology, } \\
& \text { St. Mary's Hospital, London, W.2. }
\end{aligned}
$$

\section{Recruitment and Training of Nurses}

Sir,-Your annotation entitled "Selection and Training of Student Nurses" (April 9, p. 1120) mentions the Report of Nursing Committee published by the Northern Ireland Hospitals Authority, 1960. This report makes clear the valid distinction between basic nursing and technical nursing, and to recruit more nurses for the basic care of patients it recommends the expansion of the facilities for training of State-enrolled assistant 